\section{Thoracic and Lumbar Sagittal Spinal Curvature Adaptations between Elite Iranian Road and Speed Cyclists}

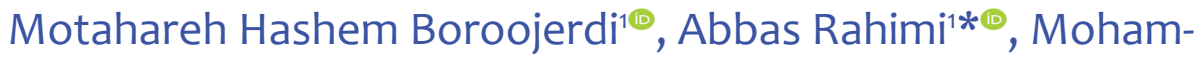 \\ mad Mohsen Roostayi', Saeed Moghaddam Talebian², Mo- \\ hammad Yousefi',3, Edgar Shamounian ${ }^{4}$, Mahmoud Norouzi ${ }^{5}$
}

\begin{abstract}
Background: Despite existing some research on the effects of professional cycling on cyclist's spinal curvature angles, no research is available concentrating on possible differences in various types of professional cycling. Road (outdoor) and speed (indoor) cyclists have different anthropometric and predominant postures during cycling. The current study aims to investigate if cyclists with different types of cycling may have dissimilar spinal curvature adaptations.

Objective: Forty-eight male subjects, including 16 elite road cyclists, 16 elite sprint cyclists and 16 non-athletes as the control group were recruited in this nonexperimental study.

Material and Methods: In this cross-sectional study, a spinal mouse was used to measure the thoracic and lumbar curvature angles in standing position.

Results: The mean values of thoracic kyphosis and lumbar lordosis angles were found as follows: $48.3 \pm 7.2^{\circ} \&-20.3 \pm 7.2^{\circ}$ for elite road cyclists; $46.6 \pm 8.1^{\circ} \&$ $-22.5 \pm 7.7^{\circ}$ for elite sprint cyclists; and $37.5 \pm 4.1^{\circ} \&-19 \pm 6.3^{\circ}$ for the control group. The results confirmed that both the road and sprint cyclists showed significantly more hyper-kyphosis posture in their thoracic region when compared to the control group $(\mathrm{p}<0.05)$.
\end{abstract}

Conclusion: All road cyclists showed no significantly higher degrees of thoracic angle relative to the sprint cyclists ( $p>0.05)$. However, all the cyclists and the control groups showed a normal range of lumbar lordosis angle. As a conclusion, the results of this study confirmed that an elite cyclist may predispose these subjects to the risk of hyper-kyphotic posture. The road cycling may result in more hyper-kyphosis due to the longer time, spent in flexed position.

Citation: Hashem Boroojerdi M, Rahimi A, Roostayi MM, Moghaddam Talebian S, Yousefi M, Shamounian E, Norouzi M. Thoracic and Lumbar Sagittal Spinal Curvature Adaptations between Elite Iranian Road and Speed Cyclists. J Biomed Phys Eng. 2021;11(3):297-304. doi: $10.31661 /$ jbpe.v0i0.2001-1058

\section{Keywords}

Lordosis; Kyphosis; Adaptations; Athletes

\section{Introduction}

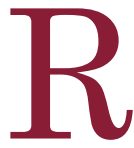

eviewing the literature reveals that long-term sports training can gradually cause specific postural adaptations in athletes. Several studies have considered sagittal spinal curvatures in different sports with predominant semi-flexed posture such as skiers, wrestlers, rowers, and paddlers [1-4]. Most of these studies reported thoracic kyphosis increases in athletes with prolonged flexed posture. On the other
${ }^{1} \mathrm{PhD}$, Department of Physiotherapy, School of Rehabilitation, Shahid Beheshti University of Medical Sciences, Tehran, Iran

${ }^{2} \mathrm{PhD}$, Department of Physiotherapy, Faculty of Rehabilitation, Tehran University of Medical Sciences, Tehran, Iran ${ }^{3} \mathrm{PhD}$, Faculty of Sport Sciences, Department of Sports Biomechanic, University of Birjand,

Birjand, Iran

${ }^{4} \mathrm{PhD}$. Department of Physical Education \& Sport Sciences (Sport Management), Islamic Azad University, Tehran, Iran

${ }^{5} \mathrm{MSc}$. Department of Physiotherapy, School of Rehabilitation, Shahid Beheshti University of Medical Sciences, Tehran, Iran

*Corresponding author: Abbas Rahimi

Department of Physiotherapy, School of Rehabilitation, Shahid Beheshti University of Medical Sciences, Tehran, Iran

E-mail: a_rahimi@sbmu. ac.ir

Received: 26 January 2020 Accepted: 7 April 2020 
side, many studies have also reported a thoracic and lumbar angles reduction in athletes with a predominantly upright posture such as rhythmic gymnasts, ballet dancers, volleyball, and basketball players [5-7]. All findings declared a positive correlation between the repetitive and dominant forward-bending or upright postures and spinal curvature angles during years of training in elite athletes. These postural changes could significantly lead to a higher multi-segmental spinal load and were associated with abnormal forces on specific elements of the spine [8]. Over the time, due to the importance of the spinal curvatures in transferring the forces along the spinal column, no changes in spinal curves may result in different musculoskeletal and motor control impairments [9]. A deep reviewing of the literature reveals some contradictions in studies of this field. A possible reason could be due to the existence of many confounding factors such as gender, age, weight, height, muscle strength, muscle length, which may play an important role in spinal curvature changes. Even in normal subjects, a very wide ranges of the curvature angles exists for the lumbar lordosis and thoracic kyphosis in different studies, resulting in the researchers suggest defining the normal lordosis angles based on the specific features of each individual in each specific population [10].

Although some inconclusive literature showed a relationship between the amounts of the lumbar lordosis angle and the presence of low back pain, a large number of studies have demonstrated a relationship between force distribution changes on the spine with some alterations in spinal sagittal curvature angles [8, 11]. Positions with increased thoracic kyphosis not only results in some changes in force transfer along with the spinal column but also increases the possibility of the hyper-kyphosis development by age. On the other hand, hyper-kyphosis posture plays an important role in musculoskeletal impairment, increased risk of falling rate, and also non-traumatic frac- tures in older adults. Therefore, detection of hyper-kyphosis at its early stage may help in reducing the rate of damage caused by this malformation.

Due to the popularity of cycling and the higher frequency of overuse injuries in these athletes [12], considering professional and elite cyclists' posture as an influential factor in hyper-kyphosis is crucial. To be a successful cyclist, maintaining the correct anthropometric and physical posture play an important role. During cycling, the aerodynamic drag force may cause a reduction in cyclists' speed and lead to much energy consumption rate. It is clear that when the cyclist's back is relatively parallel to the ground, their drag force is less than an upright position [13].Therefore, remaining in the forward bending posture for a longer time is essential particularly for road cyclists.

A number of studies measured the spinal curvatures of elite cyclists in sagittal plane [3, $4,14]$. Some studies have reported a hyperkyphotic posture in the standing position only in highly trained cyclists, as well as a neutral lumbar angle. In addition, greater lumbar flexion and enhancement of anterior pelvic tilt during cycling were explored in elite cyclists when compared to the non-athletes that occurred following a long time aerodynamic stooped position. Van Hoof et al. (2012) reported more flexion of the lower lumbar spine in elite cyclists with low back pain in comparison with the healthy cyclists [15].

Reviewing the literature reveals that most of the previous studies have focused on comparing the cyclists' postures with different athletes, particularly with athletes in standing postures. Since one of the most important factors on cyclists such as posture is the time that they are in stooped position, it is logical to investigate if the type of cycling, including the road, sprint and mountain cycling is also an important issue. Numerous studies have indicated a functional plasticity in different muscle fibers in human occurring based upon the prin- 
ciple of specificity following muscle training. Referred to these studies, it can be concluded that athletes involved in long-distance sports, such as road cycling have noticeably more slow muscle fibers (type I) in comparison with the athletes involved in sprint type exercises [16]. Due to the different physiological structures of muscles in speed and endurance athletes [17], it seems that investigating the postures of these cyclist separately is useful. The current study aims to survey the thoracic and lumbar curvature angles in sagittal plane in elite road and sprint cyclist.

\section{Material and Methods}

In this cross-sectional study, thirty-two elite male cyclists, including 16 road and 16 sprint cyclists who played in Iran cycling national team, were participated. Sixteen age-sex matched non-athletes were also recruited as the control group. All cyclists should have at least 3 years of experience in cycling in the national team. The subjects excluded if they reported a permanent thoracic or lumbar pain lasting for 3 months or more had no spinal structural pathology, no postural problems in frontal plane such as scoliosis and no abdominal or spinal surgery at all. The non-athlete subjects had no professional sport history. All subjects signed an informed consent form, approved by the Human Subjects Committee, the University of Shahid Beheshti, and Medical Sciences prior to participation in this study. Some information such as the subjects' personal information and the history of taking part in the professional cycling were recorded in an author-made information sheet prepared for this study.

A spinal mouse (Idiag, Voletswil Company, Switzerland) was used in this study in order to measure the thoracic and lumbar curvatures in the standard standing position. The spinal mouse has already been approved by some researchers as a highly reliable non-invasive device for measuring the spinal curvatures [18, 19]. To control the diurnal changes in mea- surement of the spinal curvatures, all records were carried out between 9:00 am and 13:00 $\mathrm{pm}$, in each testing day. All tests were repeated three times by the same technician. The subjects were tested in the standing comfortable position with hands hanging beside their bodies with an exposed trunk and the $\mathrm{C} 7$ spinous process and the top of the anal cleft were determined and marked by the examiner [20]. Then, the spinal mouse device was placed on the defined C7 spinous process and moved along the midline of the spine to the top of the anal cleft at a constant speed. The spine's topography was recorded in the sagittal plane and repeated for three times. Prior to the main study, an intra-tester reliability study was carried out on the cyclists and control groups to confirm the repeatability of the spinal mouse. In order to complete the intra-tester reliability assessment, 15 volunteers were assessed twice by the same examiner. For this purpose, the participants' thoracic and lumbar curvatures were measured three times and repeated after 30 minutes.

A Kolmogrov-Smirnov test was used to examine the normality of variable distribution and the results showed a normal distribution. The intra-class correlation coefficient (ICC) was applied to assess the relative and absolute intra-tester reliability of the measurements. The one-way mixed-design ANOVA and the Bonferroni post hoc test were used to compare the thoracic and lumbar curvatures among the groups. A Pearson's correlation coefficient test was also used to find out if any correlation exists between the number of years of the cyclists' experience and hours of exercising to cycling with the amount of thoracic and lumbar curve angles. The same correlation test was also used to define any correlation between the height and weight with the kyphosis angle of the participants.

\section{Results}

Demographic characteristics are shown in Table 1. According to the Shapiro-Wilk test, 
Table 1: Descriptive characteristics of road and sprint cyclists and non-athletics group

\begin{tabular}{cccc} 
& $\begin{array}{c}\text { Road cyclists }(\mathbf{n = 1 6 )} \\
\text { Mean (SD) }\end{array}$ & $\begin{array}{c}\text { Sprint cyclists } \\
(\mathbf{n}=16)\end{array}$ & $\begin{array}{c}\text { Non-athletics group } \\
(\mathbf{n}=\mathbf{1 6})\end{array}$ \\
\hline Age & $24.1(4.2)$ & $25.3(6.6)$ & $22.6(3.6)$ \\
\hline Height(m) & $179.7(5.6)$ & $179.1(3.4)$ & $179.1(8.6)$ \\
\hline Weight(kg) & $71.6(6.5)$ & $80.6(7)$ & $73.7(15.9)$ \\
\hline BMI (kg・m-2) & $22.2(1.8)$ & $25.1(2)$ & $22.9(3.7)$ \\
\hline Training time (years) & $6(2.8)$ & $7(3.8)$ & - \\
\hline Training time (hourslweek) & $21.21(7.1)$ & $16.38(4.4)$ & -
\end{tabular}

BMI: Bady Mass Index

no significant differences were seen in the subjects' height, weight, BMI and age among the groups. The ICC values for reliability assessment demonstrated a high intra-tester reliability for spinal mouse measurement of the thoracic and lumbar curves (0.97 and 0.94, respectively). The result of one-way mixeddesign ANOVA showed significant differences $(p<0.05)$ in thoracic kyphosis between the two groups of cyclists and the control group; however, no statistically significant differences were found in lumbar lordosis between the experimental and the control groups (Table 2).

Although both groups exhibited a greater thoracic kyphosis angle than the non-athletes, no significant differences were observed in the thoracic and lumbar curves of the road and sprint cyclists. In addition, there was no correlation between the athletes' years of experiences (the duration of cycling) and hours of exercising to cycling with their spinal curve angles. Moreover, no significant relationship was observed between the BMI, weight or height of the subjects and the increased kyphosis angle.

\section{Discussion}

The current data revealed that most cyclists, regardless of the type of cycling, have a hyper-kyphotic posture relative to the normal people which was in agreement with the previous studies. It should be considered that no significant differences were found in terms of age, height and weight as influencing factors among the three groups. Due to the lengthy drill time cycling in road cyclists, they showed no significantly more hyper-kyphotic posture than the sprint cyclists.

The lumbar curvature angel didn't show any differences between road and sprint cyclists groups. Also, this variable showed no differences between non-athletics subjects and cyclist, which was in agreement with the previous studies [3, 4, 14]. Therefore, it seems that despite the longtime excessive forward bending and the anterior pelvic tilt during cycling,

Table 2: Mean values (SD) of the thoracic and lumbar spinal curvatures in road and sprint cyclists and non-athletics groups

\section{Road cyclists Sprint cyclists Non-athletics group p-value}

\begin{tabular}{ccccc}
\hline Thoracic kyphosis & $48.17(7.2)$ & $46.63(8.1)$ & $37.52(4.1)$ & 0.00 \\
\hline Lumbar lordosis & $-20.32(7.2)$ & $-22.47(7.7)$ & $-18.97(6.3)$ & 0.41
\end{tabular}


the cyclists didn't show any changes in their lumbar lordosis angle when was tested in normal standing position. Since the lumbar spine is inherently more mobile than the thoracic spine region [21], it might be assumed that the tolerability of the lumbar region is more to accept the repeated and persistent forward bending postures. On the other hand, the specific anatomy nature of the spinal extensor muscles leads to the special motor control of these muscles to provide the possibility of the independent movement pattern in different segments of the spine $[22,23]$. The motor control independency could prove the variability seen in the adaption behavior of the thoracic and lumbar regions.

Muyor et al. [3] suggested that the thoracic hyper-kyphosis may not be directly associated to the positions adopted on the bicycle. Accordingly, cyclists with thoracic hyper-kyphosis posture in standing position showed more normal thoracic angular values throughout the sitting on the bicycle. Therefore, they reported that some other factors may be responsible for this postural adaptation.

In the current study, no relationship was found among the number of training experience years, cumulative training hours, and the spinal curves changes in cyclist groups. However, in 2000, Wojtys et al. investigated the relationship between the long hours of practicing/exercising to training, and the sagittal spinal curvature in other sports such as football, gymnastics, ice hockey, and swimming [24]. These studies showed a significant enhancement in lumbar and thoracic angles of children with more training exposures. The relevance in this study could be due to the range of participants age (8-18 years old), and this reality that the immature spine is more flexible and prone to be directly influenced by the mechanical forces. Since the participants of the current study were adults with mature and firm spine, the spinal curvatures changes had no direct relationship with their cycling training hours.
A hyper-kyphosis posture is known as a multifactorial musculoskeletal disorder that could be affected by various factors such as age, weight, height, muscle strength and length, mal-postures [25-27]. Consequently determining a particular factor as a most important effective element in hyper-kyphosis posture is quite difficult.

A study in age-related hyper-kyphosis individuals showed that a body weight reduction resulted in reduced thoracic kyphosis angle in older people [28]. It should be considered that in fact in aging processing, the muscles atrophy happens more in fast twitch muscle fibers (type II) than the slow muscle fibers (type 1) [25]. This shows that there is a possible relationship between decreasing the amount of fast muscle fibers and the thoracic kyphosis angle improvement. On the other hand, numerous studies showed a negative relationship between muscle strength and hyper kyphosis angle [22, 29, 30]. Since the spinal extensor muscles are often more postural and endurance type, most researchers have focused on the correlation between the strength of these muscles and the hyper-kyphosis posture [29, 30]. However, no correlation was found between the weights and heights of the subjects of the current study and increasing kyphosis angles between the two groups. This might be due to the homogeneity of participant's height and weight in this study.

As mentioned before, the road and sprint cyclists are different in musculoskeletal structures due to the different types of muscles and physiological adaption in response to training. In fact, we expect that sprint cyclist has more percentage of type 2 muscle fibers relative to the road cyclists. In this study, sprint cyclists with more muscular body style showed less hyper-kyphosis posture than the road cyclists, although there is no statically significant value.

\section{Conclusion}

Although cyclists' thoracic and lumbar 
curves in sagittal plane were evaluated in some of the previous studies, none of them investigated the possible variances of the spinal curvature angles between the sprint and road cyclists. Due to the several differences in physiological nature of their muscle structure and the specific type of each groups' training program, identification of the factors involved in cyclists thoracic and lumbar curvatures could help to prepare corrective exercise program for these athletes. The results of the current study revealed no significantly different thoracic and lumbar curve angles between the elite road and sprint cyclists.

\section{Acknowledgment}

This work was supported by The University of Shahid Beheshti, and Medical Sciences. We thank our colleagues from School of Rehabilitation, Shahid Beheshti University of Medical Sciences, who provided insight and expertise that greatly assisted the research.

\section{Conflict of Interest}

None

\section{References}

1. Rajabi R, Doherty P, Goodarzi M, Hemayattalab R. Comparison of thoracic kyphosis in two groups of elite Greco-Roman and freestyle wrestlers and a group of non-athletic participants. British Journal of Sports Medicine. 2008;42(3):229-32. doi: 10.1136/ bjsm.2006.033639.

2. López-Miñarro PA, Alacid F, Rodríguez-García $\mathrm{PL}$. Comparison of sagittal spinal curvatures and hamstring muscle extensibility among young elite paddlers and non-athletes. International Sport Med Journal. 2010;11(2):30112.

3. Muyor JM, López-Miñarro PA, Alacid F. Spinal posture of thoracic and lumbar spine and pelvic tilt in highly trained cyclists. Journal of Sports Science and Medicine. 2011;10(2):35561. PubMed PMID: 24149883. PubMed PMCID: PMC3761866.

4. Muyor JM, López-Miñarro PA, Alacid F. Comparison of sagittal lumbar curvature between elite cyclists and non-athletes. Science \& Sports. 2013;28(6):e167-73. doi: 10.1016/j. scispo.2013.04.003.

5. Kums T, Ereline J, Vain A. Spinal curvature and trunk muscle tone in rhythmic gymnasts and untrained girls. Journal of Back and Musculoskeletal Rehabilitation. 2007;20(2-3):8795. doi: 10.3233/BMR-2007-202-306.

6. Grabara M. Comparison of posture among adolescent male volleyball players and nonathletes. Biology of Sport. 2015;32(1):79. doi: 10.5604/20831862.1127286. PubMed PMID: 25729154. PubMed PMCID: PMC4314608.

7. Grabara M. Sagittal spinal curvatures in adolescent male basketball players and non-training individuals-a two-year study. Science \& Sports. 2016;31(5):e147-53. doi: 10.1016/j. scispo.2016.01.010.

8. Bruno AG, Anderson DE, Agostino JD, Bouxesin M. The effect of thoracic kyphosis and sagittal plane alignment on vertebral compressive loading. Journal of Bone and Mineral Research. 2012;27(10):2144-51. doi: 10.1002/ jbmr.1658. PubMed PMID: 22589006. PubMed PMCID: PMC3431452.

9. Iorio JA, Jakoi AM, Singla A. Biomechanics of degenerative spinal disorders. Asian Spine Journal. 2016;10(2):377-84. doi: 10.4184/ asj.2016.10.2.377. PubMed PMID: 25114783. PubMed PMCID: PMC4843079.

10.Do Rosário JL. Biomechanical assessment of human posture: a literature review. J Bodyw Mov Ther. 2014;18(3):368-73. doi: 10.1016/j. jbmt.2013.11.018. PubMed PMID: 25042306.

11. Keorochana G, Taghavi S, Lee KB, Yoo JH. Effect of sagittal alignment on kinematic changes and degree of disc degeneration in the lumbar spine: an analysis using positional MRI. Spine. 2011;36(11):893-8. doi: 10.1097/ BRS.0b013e3181f4d212. PubMed PMID: 21242877.

12. Tin ST, Woodward A, Ameratunga S. Injuries to pedal cyclists on New Zealand roads, 19882007. BMC Public Health. 2010;10:655. doi: 10.1186/1471-2458-10-655.

13.Defraeye T, Blocken B, Koninckx E, Hespel P. Aerodynamic study of different cyclist positions: CFD analysis and full-scale wind-tunnel tests. Journal of Biomechanics. 2010;43(7):1262-68. doi: 10.1016/j.jbio- 
mech.2010.01.025. PubMed PMID: 20171640.

14.McEvoy MP, Wilkie K, Williams MT. Anterior pelvic tilt in elite cyclists-A comparative matched pairs study. Physical Therapy in Sport. 2007;8(1):22-29. doi: 10.1016/j. ptsp.2006.09.022.

15.Van Hoof W, Volkaerts K, O'Sullivan K, Verschueren S. Comparing lower lumbar kinematics in cyclists with low back pain (flexion pattern) versus asymptomatic controls-field study using a wireless posture monitoring system. Manual Therapy. 2012;17(4):312-17. doi: 10.1016/j.math.2012.02.012. PubMed PMID: 22436688.

16. Malisoux L, Francaux M, Theisen D. What do single-fiber studies tell us about exercise training? Medicine \& Science in Sports \& Exercise. 2007;39(7):1051-60. doi: 10.1249/ mss.0b13e318057aeb. PubMed PMID: 17596771.

17.Aagaard P, Anderson JL. Effects of resistance training on endurance capacity and muscle fiber composition in young top-level cyclists. Scandinavian Scand J Med Sci Sports. 2011;21(6):e298-307. doi: 10.1111/j.16000838.2010.01283.x. PubMed PMID: 17596771.

18.Livanelioglu A, Kaya F, Nabiyev V, Demirkiran G. The validity and reliability of "Spinal Mouse" assessment of spinal curvatures in the frontal plane in pediatric adolescent idiopathic thoraco-lumbar curves. European Spine Journal. 2016;25(2):476-82. doi: 10.1007/s00586015-3945-7. PubMed PMID: 25900295.

19. Barrett E, McCreesh K, Lewis J. Reliability and validity of non-radiographic methods of thoracic kyphosis measurement: a systematic review. Manual Therapy. 2014;19(1):10-7. doi: 10.1016/j.math.2013.09.003. PubMed PMID: 24246907.

20.López-Miñarro PA, Vaquer R, Alacid F, Isorna $M$. Comparison of sagittal spinal curvatures and pelvic tilt in highly trained athletes from different sport disciplines. Kinesiology. 2017;49(1). doi: 10.26582/k.49.1.2.

21.Post R, Leferink V. Spinal mobility: sagittal range of motion measured with the SpinalMouse, a new non-invasive device. Arch Orthop Trauma Surg. 2004;124(3):187-92. doi: 10.1007/s00402-004-0641-1. PubMed PMID:
14968367.

22. Roghani T, Khalkhalizavieh M, Talebian S, Akbarzadeh A. Back Muscle Function in Older Women With Age-Related Hyperkyphosis: A Comparative Study. J Manipulative Physiol Ther. 2019;42(4):284-94. doi: 10.1016/j. jmpt.2018.11.012. PubMed PMID: 31257003.

23. Hsu CJ, Chang YW, Chou WY, Chiou CP, Chang WN, Wong CY. Measurement of spinal range of motion in healthy individuals using an electromagnetic tracking device. Journal of Neurosurgery: Spine. 2008;8(2):135-42. doi: 10.3171/SPI/2008/8/2/135. PubMed PMID: 18248285.

24.Wojtys EM, Ashton-Miller JA, Huston LJ. The association between athletic training time and the sagittal curvature of the immature spine. The American Journal of Sports Medicine. 2000;28(4):490-98. doi: 10.1177/03635465000280040801. PubMed PMID: 10921639.

25. Katzman W, Cawthon PM, Hicks GE. Association of spinal muscle composition and prevalence of hyperkyphosis in healthy community-dwelling older men and women. J Gerontol A Biol Sci Med Sci. 2011;67(2):19195. doi: 10.1093/gerona/glr160. PubMed PMID: 21878482. PubMed PMCID: PMC3297013.

26.Ashton-Miller JA. Thoracic hyperkyphosis in the young athlete: a review of the biomechanical issues. Curr Sports Med Rep. 2004;3(1):47-52. doi: 10.1249/00149619200402000-00009. PubMed PMID: 14728914.

27.Aroeira RM, Estevam B, Pertence AE, Greco $\mathrm{M}$, Tavares JM. Non-invasive methods of computer vision in the posture evaluation of adolescent idiopathic scoliosis. J Bodyw Mov Ther. 2016;20(4):832-43. doi: 10.1016/j. jbmt.2016.02.004. PubMed PMID: 27814864.

28. Kado DM, Huang MH, Karlamangla AS, Cawthon P, Katzman W, Hillier TA, Ensrud $\mathrm{K}$, Cummings SR. Factors associated with kyphosis progression in older women: 15 years' experience in the study of osteoporotic fractures. J Bone Miner Res. 2013;28(1):17987. doi: 10.1002/jbmr.1728. PubMed PMID: 22865329. PubMed PMCID: PMC3693545.

29.Dastmanesh S, Eskandari E, Shafiee GH. Relationship Between Physical Fitness Abilities, 
Trunk Range of Motion and Kyphosis in Junior High School Students. Middle-East Journal of Scientific Research. 2013;13(1):79-84. doi: 10.5829/idosi.mejsr.2013.13.1.6482.

30. Hirano K, Imagama SH, Hasegawa Y. Impact of back muscle strength and aging on locomotive syndrome in community living Japanese women. Nagoya J Med Sci. 2013;75(1-2):47. PubMed PMID: 23544268. PubMed PMCID: PMC4345697. 